\title{
AKTIVITAS EKSTRAK KULIT BUAH SEMANGKA MERAH (Citrullus lanatus) TERHADAP Candida albicans DAN Bacillus subtilis
}

\author{
Gita Susanti ${ }^{1}$, Yunilda Rosa ${ }^{2}$, Neti Nuramelia Putri ${ }^{3}$ \\ 1,2,3. Prodi S1 Farmasi, STIK Siti Khadijah Palembang \\ Email : gita_xf@yahoo.com
}

\begin{abstract}
ABSTRAK
Kulit buah semangka adalah salah satu bagian buah semangka yang tidak dikonsumsi dan biasanya dibuang tanpa ada pemanfaatan lebih lanjut. Tujuan penelitian ini adalah untuk mengetahui aktivitas antibakteri dan antijamur ekstrak kulit semangka merah (Citrullus lanatus) terhadap Bacillus subtilis dan Candida albicans. Ekstrak konsentrasi 2,5\%, $5 \%, 10 \%, 20 \%$, dan $40 \%$ diperoleh dengan metode maserasi menggunakan pelarut etanol $96 \%$. Aktivitas antibakteri diketahui dengan metode dilusi untuk mengetahui konsentrasi Hambat Minimum (KHM) dan metode difusi untuk mengetahui kekuatan ekstrak. Hasil penelitian menunjukkan bahwa KHM ekstrak kulit buah semangka terhadap Candida albicans dan Bacillus subtilis berada pada konsentrasi 20\%, dengan diameter zona bening 11,4 mm terhadap Bacillus subtilis, dan 11,3 mm terhadap Candida albicans. Berdasarkan hasil penelitian, dapat disimpulkan bahwa ekstrak kulit semangka merah memiliki aktivitas antibakteri dan antijamur terhadap bakteri Bacillus subtilis dan jamur Candida albicans dengan kategori kuat.
\end{abstract}

Kata kunci : Kulit Buah Semangka Merah, Candida albicans, Bacillus subtilis, Konsentrasi Hambat Minimum

\begin{abstract}
Watermelon rind is the part of the watermelon that is not consumed and is usually discarded without further use. The purpose of this study was to determine the antibacterial and antifungal activity of red watermelon skin extract (Citrullus lanatus) to Bacillus subtilis and Candida albicans. Extract concentrations of 2.5\%, 5\%, 10\%, 20\%, and 40\% were obtained by maceration method using $96 \%$ ethanol as solvent. Antibacterial activity was determined by the dilution method to determine the minimum inhibitory concentration (MIC) and the diffusion method to determine the strength of extract activity. The results showed that the MIC of watermelon rind extract to Candida albicans and Bacillus subtilis was at a concentration of $20 \%$, with a clear zone diameter of $11.4 \mathrm{~mm}$ to Bacillus subtilis, and $11.3 \mathrm{~mm}$ to Candida albicans. Based on the research, it can be ascertained that the red watermelon rind extract has strong antifungal and activity to Bacillus subtilis and Candida albicans.
\end{abstract}

Keywords : Red Watermelon Rind, Candida albicans, Bacillus subtilis, Minimum Inhibitory Concentration 


\section{PENDAHULUAN}

Penyakit infeksi merupakan salah satu masalah kesehatan di negara berkembang termasuk Indonesia. Menurut (WHO, 2015), sekitar $83 \%$ kematian disebabkan oleh penyakit infeksi, kelahiran prematur dan kondisi gizi yang di dapatkan oleh anak-anak. Setiap tahun infeksi menewaskan 3.5 juta orang yang sebagian besar terdiri dari anakanak miskin (WHO, 2014). Data lain menyebutkan bahwa pada tahun 2013, terdapat 6,3 juta anak-anak di bawah 5 tahun meninggal, dimana setiap harinya terjadi sekitar 17.000 kematian (WHO, 2015). Adapun salah satu diantara bakteri dan jamur yang dapat menyebabkan infeksi tersebut adalah bakteri Bacillus subtilis dan jamur candida albicans (Jawetz, et al., 2013).

Bakteri Bacillus subtilis merupakan bakteri gram positif, umumnya bakteri ini dapat menyebabkan meningitis, endokarditis, infeksi mata dan lain-lain (Rahmawati, 2015). Bacillus subtilis dapat ditemukan di saluran pencernaan manusia seperti di dalam usus apabila jumlah bakteri terlalu banyak di dalam usus akan menyebabkan diare yang ditularkan melalui kontaminasi makanan dan minuman (Arumbinang, dkk, 2017). Sedangkan jamur Candida albicans merupakan jamur yang sering hidup di area yang lembab yang disebabkan oleh kurangnya kebersihan sehingga dapat menyebabkan infeksi. Infeksi jamur ini biasanya terjadi di kulit, mulut dan organ intim. Jika tidak mendapatkan penanganan secara cepat, infeksi akibat jamur ini dapat menyebar kebagian tubuh lain seperti usus, ginjal, jantung otak, dan lain-lain (Pratiwi, 2018).

Secara umum, penyakit infeksi dapat disembuhkan dengan menggunakan antibiotik. Salah satu masalah global yang sedang dihadapi adalah resistensi bakteri terhadap antibiotik, baik di negara berkembang maupun negara maju. Oleh karena itu, dibutuhkan beberapa tindakan untuk mengurangi masalah ini dengan mengontrol penggunaan antibiotik, mengembangkan penelitian untuk mengendalikan resistensi secara genetik, dan penemuan obat baru baik sintetik maupun yang berasal dari alam (Karadi, et al, 2011). Salah satu pilihan alternatif untuk mengontrol penggunaan antibiotik adalah dengan menggunakan obat tradisional yang berasal dari tanaman sebagai obat alternatif terhadap infeksi bakteri dan jamur dengan efek samping yang lebih kecil dan mudah didapatkan (Bota, 2015).

Salah satu tanaman obat alternatif yang memiliki khasiat sebagai antibakteri adalah semangka. Kebanyakan orang di Indonesia hanya menggunakan semangka sebagai hidangan penutup makanan dan dikonsumsi sebagai buah segar atau sebagai minuman. Mayoritas masyarakat hanya mengkonsumsi bagian daging buah berwarnah merah atau kuning saja sedangkan kulit semangka hanya dibuang dan menjadi limbah tanpa ada pemanfaatan lebih lanjut. Kulit buah semangka sama pentingnya dengan bagian daging buah semangka (Rimando, 2015). Meski jarang dikonsumsi, kulit buah semangka memiliki khasiat dapat mencegah pertumbuhan bakteri dan jamur. Beberapa peneliti telah membuktikan bahwa kulit buah semangka memiliki aktivitas farmakologi. Fungsi terapeutik semangka yakni antibakterial, antifungal (Deshmukh, 2015).

Kulit buah semangka kaya akan vitamin mineral, enzim, dan klorofil. Vitamin-vitamin yang terdapat pada kulit buah semangka meliputi vitamin $\mathrm{C}$, vitamin $\mathrm{A}$, vitamin $\mathrm{B} 2$, vitamin B6. Menurut hasil penelitian yang dilakukan oleh Oseni dan Okoye (2013), Kulit buah semangka mengandung serat yang dapat menyehatkan saluran cerna dan baik untuk menyehatkan tubuh. Saluran cerna yang baik dapat menghindari diri dari penyakit infeksi (Maghfiroh, et al., 2021).

Berdasarkan uraian di atas, maka dilakukan penelitian untuk membuktikan aktivitas antibakteri dan antijamur kulit buah semangka merah terhadap pertumbahan bakteri Bacillus subtilis dan jamur Candida albicans.

\section{METODE PENELITIAN Desain Penelitian}

Penelitian ini menggunakan jenis penelitian eksperimental dengan menggunakan kulit buah semangka merah 
(Citrullus lanatus) untuk menentukan Konsentrasi Hambat Minimum (KHM) dan Kekuatan terhadap bakteri Bacillus subtilis dan jamur Candida albicans. Penelitian dilaksanakan di Laboratorium Mikrobiologi Farmasi STIK Siti Khadijah Palembang pada bulan Juli sampai Agustus 2021

\section{Persiapan Sampel}

Buah semangka merah dikupas kemudian diambil kulitnya dibersihkan dari pengotor dengan air yang mengalir sampai bersih kemudian ditiriskan lalu di potong dengan panjang lebih kurang $2 \mathrm{~cm}$ dan ketebalan $1 \mathrm{~cm}$ kemudian dikeringkan dengan cara di jemur dibawah sinar matahari dengan ditutupi kain hitam. Selain itu, sampel yang telah kering dihaluskan dengan blender sampai menjadi serbuk, dan diperoleh simplisia kulit semangka merah (Citrullus lanatus). kemudian ditambahkan pelarut etanol 96\% dan dimaserasi selama 3x24 jam lalu disaring kemudian hasil ekstrak cair dikumpulkan dan diuapkan dengan Rotary evaporator untuk mendapatkan ekstrak kental.

\section{Penapisan Fitokimia}

Penapisan fitokimia menggunakan metode strandar untuk menentukan kandungan alkaloid, flavonoid, saponin, tannin, fenol, dan terpenoid dalam ekstrak etanol kulit buah semangka merah.

\section{Pembuatan Suspensi Bakteri}

Biakan bakteri disubkultur dalam media Nutrient Agar (NA) diinkubasi pada $37^{\circ} \mathrm{C}$ selama 24 jam. Hasil subkultur biakan bakteri diambil dengan jarum ose dan dimasukkan kedalam tabung reaksi yang berisi $9 \mathrm{ml}$ larutan $\mathrm{NaCl} 0.9 \%$. setelah itu dihomogenkan dengan cara divorteks dan disamakan kekeruhannya dengan standar Mc. Farland 0,5 untuk mendapatkan bakteri sebanyak $10^{8} \mathrm{cfu} / \mathrm{ml}$.

Biakan jamur disubkultur dalam media Sabouroud Dextrose Agar (SDA) diinkubasi pada $37^{\circ} \mathrm{C}$ selama 24 jam. Hasil subkultur biakan jamur diambil dengan jarum ose dan dimasukkan kedalam tabung reaksi yang berisi $9 \mathrm{ml}$ larutan $\mathrm{NaCl} 0.9 \%$. setelah itu dihomogenkan dengan cara divorteks dan disamakan kekeruhannya dengan standar Mac. Farland 0,5.

\section{Penentuan Aktivitas Antibakteri}

Tabung reaksi disiapkan 5 buah untuk setiap pengenceran ekstrak masing-masing tabung reaksi diberi label, tabung 1-5 berisi Nutrient Broth (NB) sebanyak $5 \mathrm{ml}$ kemudian ekstrak kulit buah semangka merah yang telah di tentukan konsentrasinya di masukkan ke dalam tabung reaksi yang berisi $N B$ dan dihomogenkan dengan vortex. Suspensi Bakteri sebanyak $1 \mathrm{ml}$ diinkokulasikan ke dalam masing-masing tabung. Tabung reaksi kemudian diinkubasikan pada suhu $37^{\circ} \mathrm{C}$ selama 24 jam. Antibiotik ciprofloxacin 10\% sebagai kontrol positif dan pelarut sebagai kontrol negatif. Kemudian dihomogenkan dan diinkubasi pada suhu $37^{\circ} \mathrm{C}$ selama 24 jam. Diamati dan dibandingkan dengan kontrol positif. KHM merupakan konsentrasi terendah ekstrak yang dapat menghambat pertumbuhan bakteri pada tabung yang jernih secara kasat mata (Cockeril dkk., 2012).

Penentuan kekuatan ekstrak terhadap bakteri dilakukan dengan (NA) yang sudah dipadatkan ke dalam cawan petri kemudian dimasukkan larutan suspensi bakteri uji. Lalu diletakkan cakram yang sudah ditetesi ekstrak kulit semangka merah sesuai konsentrasi yang telah di tentukan. Kemudian diinkubasi selama 18-24 jam pada suhu $37^{\circ} \mathrm{C}$, aktivitas bakteri dapat dilihat jika tidak ada pertumbuhan bakteri yang di tandai dengan terbentuknya zona bening.

\section{Penentuan Aktivitas Antijamur}

Tabung reaksi disiapkan 5 buah untuk setiap pengenceran ekstrak masing-masing tabung di beri label, tabung 1-5 berisi Sabouroud Dextrose Broth (SDB) Sebanyak 5 ml kemudian ekstrak kulit semangka merah yang telah di tentukan konsentrasinya di masukkan ke dalam tabung reaksi berisi SDB dan dihomogenkan dengan vortex, 97uspense Jamur sebanyak $1 \mathrm{ml}$ diinkokulasikan ke dalam masing-masing tabung, kemudian di vortex. Tabung reaksi kemudian diinkubasikan pada suhu $37^{\circ} \mathrm{C}$ selama 24 jam. Antibiotik Ketokonazole sebagai kontrol positif dan 
pelarut sebagai kontrol negatif. Kemudian di homogenkan dan diinkubasikan pada suhu $37^{\circ} \mathrm{C}$ selama 24 jam. Kemudian diamati dan dibandingkan dengan kontrol positif. KHM merupakan konsentrasi terendah ekstrak yang dapat menghambat pertumbuhan jamur pada tabung yang jernih secara kasat mata.

Penentuan kekuatan ekstrak terhadap jamur dilakukan dengan SDA yang sudah dipadatkan ke dalam cawan petri kemudian dimasukkan larutan suspensi jamur uji. Lalu diletakkan cakram yang sudah di ditetesi ekstrak kulit semangka merah sesuai konsentrasi yang telah ditentukan. Kemudian diinkubasi selama $18-24$ jam pada suhu $37^{\circ} \mathrm{C}$, aktivitas jamur dapat dilihat jika tidak ada pertumbuhan jamur yang ditandai dengan terbentuknya zona bening.

\section{HASIL PENELITIAN \\ Hasil Ekstraksi}

Proses ektraksi dilakukan dengan metode maserasi. Sebanyak 500 gram simplisia kulit buah semangka merah diekstraksi dengan metode maserasi diperoleh ekstrak kental 38 gram. Rendemen ekstrak kuliat buah semangka merah adalah $7 \%$.

Tabel 1.

Hasil penapisan fitokimia ekstrak

\begin{tabular}{llc}
\hline \multicolumn{1}{c}{ Senyawa } & \multicolumn{1}{c}{ Pereaksi } & Hasil \\
\hline Alkoloid & $\mathrm{HCl} 2 \mathrm{~N}$, Dragendrof & + \\
\hline Flavonoid & Magnesium, $\mathrm{HCl}$ pekat & + \\
\hline Saponin & Aquadest & + \\
\hline Tanin & Larutan $\mathrm{FeCl}_{3} 1 \%$ & + \\
\hline Fenol & Larutan $\mathrm{FeCl}_{3} 1 \%$ & + \\
\hline Terponoid & Kloroform & \\
\hline \\
\hline
\end{tabular}

\section{Hasil Penapisan Fitokimia}

Hasil penapisan fitokimia menunjukkan bahwa ekstrak kulit buah semangka merah mengandung senyawa alkaloid, flavonoid, saponin, tannin, dan terpenoid. Hasil penapisan fitokimia dapat dilihat pada Tabel 1 .
Tabel 2.

Hasil Uji KHM Ekstrak

\begin{tabular}{lcc}
\hline $\begin{array}{c}\text { Konsentrasi } \\
\text { Ekstrak }\end{array}$ & $\begin{array}{c}\text { Bacillus } \\
\text { subtilis }\end{array}$ & $\begin{array}{c}\text { Candida } \\
\text { albicans }\end{array}$ \\
\hline $2,5 \%$ & + & + \\
\hline $5 \%$ & + & + \\
\hline $10 \%$ & + & + \\
\hline $20 \%$ & - & - \\
\hline $40 \%$ & - & - \\
\hline Kontrol $(+)$ & - & - \\
\hline Kontrol $(-)$ & + & + \\
\hline
\end{tabular}

Kontrol (+) Bacillus subtilis : Ciprofloxacin 10\%

:Ciprofloxacin Kontrol (-) bakteri : Aquadest

Kontrol (+) Candida albicans : Ketokonazol 10\%

:Ketokonazole

Kontrol (-) : Aquadest : Aquadest

+ : Ada kekeruhan : Ada Kekeruhan

- : Tidak ada kekeruhan : Tidak Ada Kekeruhan

\section{Hasil Penentuan Aktivitas Antibakteri dan Antijamur}

Hasil uji KHM ekstrak menunjukkan bahwa pada konsentrasi $20 \%$ sudah bisa menghambat pertumbuhan bakteri Bacillus Subtilis dan jamur Candida albicans. Hasil uji KHM pada Bacillus subtilis dan Candida albicans dapat dilihat pada Tabel 2.

Hasil Uji kekuatan Ekstrak Kulit Semangka merah Pada Jamur Candida Albicans dan terhadap bakteri Bacillus subtilis menunjukkan bahwa ekstrak 2,5\%,5\%, dan $10 \%$ memiliki kekuatan kategori sedang, ekstrak 20\% dan $40 \%$ memiliki kekuatan kategori kuat, sedangkan pada kontrol positif ciprofloxacin memiliki kekuatan kategori sangat kuat dan kontrol positif ketokonazol memiliki kekuatan kategori kuat. Hasil uji kekuatan ekstrak dapat dilihat pada Tabel 3.

Tabel 3.

Hasil uji kekuatan ekstrak

\begin{tabular}{lcc}
\hline $\begin{array}{c}\text { Konsentrasi } \\
\text { Ekstrak }\end{array}$ & $\begin{array}{c}\text { Zona bening } \\
\text { B. subtilis } \\
(\mathrm{mm})\end{array}$ & $\begin{array}{c}\text { Zona bening } C . \\
\text { albicans } \\
(\mathrm{mm})\end{array}$ \\
\hline $2,5 \%$ & 6,8 & 7,5 \\
\hline $5 \%$ & 8,6 & 8,5 \\
\hline $10 \%$ & 9,5 & 9,1 \\
\hline $20 \%$ & 11,4 & 11,3 \\
\hline $40 \%$ & 14,6 & 13,7 \\
\hline Kontrol $(+)$ & 22,5 & 17,7 \\
\hline Kontrol $(-)$ & 0 & 0 \\
\hline
\end{tabular}


Kontrol (+) Bacillus subtilis : Ciprofloxacin 10\% :Ciprofloxacin

Kontrol(-)bakteri : Aquadest

Kontrol (+) Candida albicans : Ketokonazol 10\%:Ketokonazole

Kontrol (-) : Aquadest

\section{PEMBAHASAN}

\section{Pembahasan Penapisan FItokimia}

Penapisan fitokimia merupakan senyawa-senyawa yang dihasilkan dari sintesis tanaman yang kebanyakan merupakan senyawa aktif yang memiliki fungsi fisiologis bagi tubuh. Uji fitokimia dilakukan untuk mengetahui metabolit sekunder dari tumbuhan. Dari hasil penapisan fitokimia kulit buah semangka merah mengandung Alkaloid, Flavonoid, Saponin, Tanin, dan terpenoid. Menurut hasil penelitian yang dilakukan oleh Oseni dan Okoye (2013), kulit buah semangka mengandung saponin, Flavonoid, terpenoid, tanin dan alkaloid, yang dimana senyawasenyawa tersebut memiliki potensi sebagai penghambat terhadap pertumbuhan bakteri dan jamur.

\section{Pembahasan Aktivitas Antibakteri dan Antijamur}

Hasil uji aktivitas antibakteri dan antijamur ekstrak etanol kulit semangka merah (Citrullus lanatus) terhadap bakteri Bacillus subtilis dan jamur Candida albicans yaitu pada masing-masing konsentrasi 2,5\%, 5\% dan 10\% menunjukkan adanya kekeruhan sedangkan pada konsentrasi $20 \%$ dan $40 \%$ menunjukkan tidak adanya kekeruhan. Hasil penelitian ini menujukkan bahwa (KHM) ekstrak etanol kulit semangka merah (Citrullus lanatus) terhadap bakteri Bacillus subtilis dan jamur Candida albicans terletak pada konsentrasi $20 \%$.

Menurut Yola Anggraeni (2019), uji aktivitas antibakteri ekstrak kulit buah semangka merah (Citrullus lanatus) terhadap bakteri Propionibacterium acne diperoleh (KHM) pada konsentrasi $15 \%$ terhadap bakteri Propionibacterium acne. Tengku Putri (2015) menyatakan bahwa KHM ekstrak kulit semangka merah (Citrullus lanatus) terhadap jamur Tricphophyton mentagrophytes terletak pada konsentrasi $20 \%$. Cara yang dilakukan yaitu dengan membuat seri pengenceran agen antimikroba pada medium cair yang ditambahkan dengan mikroba uji (Pratiwi, 2018).

Hasil uji kekuatan ekstrak kulit buah semangka merah (Citrullus lanatus) terhadap bakteri Bacillus subtilis dan jamur Candida albicans menyatakan bahwa konsentrasi ekstrak 20\% dan antibiotik ketokonazole memiliki kekuatan yang sama yaitu kuat.

Lolita Redhy (2018) melakukan penelitian aktivitas ekstrak kulit buah semangka merah (Citrullus lanatus) terhadap Candida albicans. Hasil penelitian menunjukkan bahwa Konsentrasi Bakteri Minimum berada pada konsentrasi 30\%. Dari hasil penelitian Anatasia Ginting (2016), kulit buah semangka merah dapat menghambat bakteri Staphylococcus aureus pada konsentrasi $30 \mathrm{mg} / \mathrm{mL}$.

Berdasarkan hasil penelitian, teori, dan penelitian terkait, dapat disimpulkan bahwa ekstrak kulit semangka merah mempunyai aktivitas antibakteri terhadap Bacillus subtilis dan antijamur terhadap Candida albicans.

\section{KESIMPULAN}

Berdasarkan hasil penelitian, dapat disimpulkan bahwa ekstrak kulit semangka merah memiliki aktivitas antibakteri dan antijamur terhadap bakteri Bacillus subtilis dan jamur Candida albicans dengan kategori kuat.

\section{SARAN}

Perlu penelitian lebih lanjut mengenai pengaruh daya antibakteri dan antijamur ekstrak kulit buah semangka merah (Citrullus lanatus) terhadap jenis bakteri dan jamur lain.

\section{DAFTAR PUSTAKA}

Anggraeni, Yola., Tika Ambrawati, Irmas Miranti, Erzaa Genatrika. 2019. Citrulla Gel dari limbah kulit buah semangka (Citrullus Lanatus (Thumb. Matsum \& Nakai)) Terhadap bakteri Propionibacterium acnes dan Staphyloccus aureus.

Arumbinang Wajdi, Syuhuud, Sri kasmiyati 
Susanti Puji Hastuti. 2017. Uji Aktivitas Antibakteri Campuran Ekstrak Biji kelor (Muntingia calabura) Terhadap Pseudomonas aerugionosa dan Bacillus subtilis. Diponegoro: Universitas Kristen Satya Wacana.

Bota Welmince, Martosupono Martanto, Rondonuwo, S Ferdy. 2015. Potensi Senyawa Minyak Sereh Wangi (Cymbopogon nardus L.) sebagai Agen Antibakteri. Jurnal.ftumj.ac.id. Seminar Nasional Sains dan Teknologi. Falkultas Teknik Universitas Muhammadiyah Jakarta, 17 November 2015. ISSN : 24071846.

Deshmukh, C.D., Jain, A. \& Tambe, M.S. 2015. Phytocemical and Pharmacological Profile of Citrullus lanatus (THUNB). Biolife an International Quarterly journal of Biology \& Life Sciences, 3(2), pp.48388 .

Dewi, Lolita Redhy Kusuma. 2018. Pengaruh pemberian ekstrak kulit semangka (Citrullus vulgaris) sebagai antijamur terhadap jamur Candida albicans.

Ginting, Anastasia. 2016. Uji Aktivitas Antibakteri Ekstrak Etanol Kulit Buah Semangka Merah Berbiji (Citrullus lanatus (Thunb) Matsum \&Nakai Terhadap Escherichia coli dan Staphylococcus aureus.

Jawetz, Melnick, Adelberg. 2013. Medical Microbiology. $26^{\text {th }}$ Edition. USA: Mc Graw Hill Company. p: 194-200.

Karadi, R. V., Arpan, S., Prarekh, P dan Parvez A. 2011. Antimicrobial Activities of Musa paradisiaca and Cocos nucifera. International Journal of Reseacrh in Pharmaceutical and Biomedikal Sciences. Vol 2: 264-267. URL: www.ijrpbsonline.com/files/032.pdf.

Maghfiroh, N. N., Prihanti, A. M., \& Purwanto, P. 2021. Daya Hambat Ekstrak Kulit Semangka (Citrullus lanatus) Terhadap Pertumbuhan Candida albicans. Pustaka Kesehatan, 9(1), 54. https://doi.org/10.19184/pk.v9i1.10825.

Oseni, O. A., \& Okoye, V.I. 2013. Studies of phytochemical and antioxidant properties of the fruit of watermelon (Citrullus lanatus (thumb)). $J$ Pharm biomed. Sci,27(27), 508-514.

Pratiwi, Sylvia T. 2018. Mikrobiologi Farmasi. Jakarta: Penerbit Erlangga.

Rahmawati, Meri. 2015. Uji Aktivitas Antimikroba Ekstrak Etanol dan air Rimpang Pacing (Costus spiralis) Terhadap Bakteri Escherichia coli, Shiggella dysentreriae, Salmonella typhimurium, bacillus subtilis, Staphyloccus aureus serta Fungi Candida albicans. Jakarta: UIN Syarif Hidayatuliah.

Rimando. 2015. Determination of citrulline in watermelon.

www.ncbi.nlm.nih.go/pubmed/16007998.

World Health Organization. 2014. Pneumonia.

Geneva: World Health Organization.

WHO World Health Statistics. 2015. Geneva:

Word Health Organization. 